\title{
AHP B ASED METHODOLOGIES FOR SUPPLIERS SELECTION: A CRITICAL REVIEW
}

\author{
Giuseppe Bruno $^{1}$, Emilio Esposito ${ }^{1}$, Andrea Genovese ${ }^{1,2}$, Renato Passaro $^{3}$ \\ ${ }^{1}$ University of Naples Federico II, ${ }^{2}$ University of Sheffield, ${ }^{3}$ University of Naples Parthenope
}

\begin{abstract}
The Supplier Selection Problem (SSP) consists of analyzing and measuring the performance of a set of suppliers in order to rank and select them with the general objective of improving the competitiveness of the entire supply system. Since many factors should be taken into account, very often conflicting each other, the problem can be tackled using multi-criteria approach. A survey of the scientific literature highlights that the most used methodology is the Analytical Hierarchy Process (AHP) with its variants.

In this paper a careful scrutiny of the papers appeared on international scientific journals in the recent years on the SSP is provided. In particular the analysis focuses on the use of AHP and its variants to solve different aspects of the problem. The results of the study allow individuating opportunities and open issues arising by the use of multi-criteria approaches, with particular reference to AHP-based models, to model the SSP.
\end{abstract}

\section{Introduction}

In an extremely competitive market context, consumers demand cheaper and higher quality products, on-time delivery and excellent after-sale services. Therefore, companies are under intense pressure to cut costs while maintaining a high level of quality and after-sale services. Various studies devoted to the analysis of customer-supplier relationships highlighted that, in order to improve the quality of the services and/or of the products provided to the final consumers, careful attention should be paid on the organization and management of the entire supply chain.

Moreover, with the trend to outsource a constantly increasing percentage of the value-chain activities, purchasing decisions become crucial. For these reasons a key role is played by the supplier evaluation process in order to set up a supply system able to rapidly react to market requirements and innovation process (Gules and Burgess, 1996; Sarkara and Mohapatrab, 2006; Saen, 2007). In particular, suppliers selection has assumed a strategic role in determining large customer firms competitiveness, specially in complex industries where suppliers play a crucial role in the creation of the added value. In these industries, customers devote more and more resources to the development of the suppliers system (Lamming et al., 1996; Krause and Ellram, 1997, O’Neal, 2006). In this perspective, suppliers selection has received extensive attention in the literature (de Boer et al., 2001; Kamann and Bakker, 2004).

Several and various approaches and methodologies have been developed to cope with this problem. However, while the number of proposals is growing, there is little empirical evidence of the practical usefulness of such tools in the supplier selection practice (de Boer and van der Wegen, 2003). In fact the methodologies are often tested on some numerical examples, with scarce emphasis on the development process and on the real appreciation by the user.

With reference to the used mathematical approaches, as the problem is intrinsically multi-objective, several papers have been focused on the definition of the appropriate multi-criteria approach to be adopted. In this context, the most used methodology is represented by the well-known Analytical Hierarchy Process (Saaty, 1980 and 1994), both as a pure approach and as combined approach, namely used together with other methodologies (fuzzy set theory, optimization, etc).

The AHP is a general theory of measurement that depends on the values and judgments of individuals and groups. In particular the method is based on an evaluation model structured in a hierarchical way and weights are assigned to each criteria or sub-criteria through pairwise comparisons using a "semantic" scale to define their relative importance. Due to this sophisticated technique to set the value of the weights which avoids the use of absolute numerical values in the judgments, the AHP has been widely applied to solve several decision problems. Nevertheless this large use, the method, as all 
the multi-criteria approaches, can be considered reliable if it is applied with awareness of its characteristics and risks of failures.

In this paper we show the results of a thorough survey of scientific papers focusing on the application of the AHP (both pure and combined approach) for the SSP. The aim is to provide a view of the current proposals and to discuss the crucial aspects, which arise when the methodology is applied.

The paper is organized as follows: in the next section the SSP is defined and illustrated. Then, the paper focuses on the literature survey. Afterwards, the use of AHP and its possible variants for the SSP is analyzed. Finally, a discussion on the crucial aspects related to the use of multi-criteria approaches and of AHP-based methods in particular is developed and conclusions are drawn.

\section{The Supplie rs' Se lection Problem (SPP)}

The evolutionary process of supply relationships underlines that suppliers are required to gain an adequate set of competencies to create a supply system capable of facing the market competitiveness. To this aim, customer firms have performed various actions and strategies: in particular a crucial importance has been assumed by the assessment processes, which represent a compulsory and critical starting point for the achievement of a collaborative customer-supplier system.

Even though the literature recognises assessment processes as articulated in different phases (de Boer et al., 2001), basically they present two mutually integrated though distinct parts (Esposito and Passaro, 2009). The first concerns the selection process (selection problem) of new suppliers for inclusion in the vendor list. Selecting the right supplier is a difficult task for the purchasing manager since suppliers possess strengths and weaknesses, which require careful evaluation. It is generally done after a ranking process (ranking problem) of a set of suppliers previously qualified. The second phase regards the monitoring and control of the suppliers' behaviour.

Since 1960s, the individuation of attributes and criteria to be considered in the SSP has constituted an attractive research area. Traditionally, vendor evaluation was fundamentally based on financial measures; recently, more and more emphasis has been devoted to other aspects, bringing multiple criteria into the evaluation process. Dickson (1966) listed 23 criteria for suppliers' selection, based on a survey of 273 purchasing manager. The analysis showed that quality, delivery and performance history could be considered, in their respective order, the three most important criteria.

Ha and Krishnan (2008) updated this set of attributes as shown in Table 1. This attribute list provides a first flavor of the complexity of the problem: many factors should be taken into account, very often conflicting each other. Moreover, some of these factors can be easily measured, while some others are qualitative concepts: the aggregation of these attributes in a final judgment about a supplier can result in a tricky problem.

Table 1. Supplier selection attributes according to Ha and Krishnan (2008) framework.

\begin{tabular}{|l|l|l|}
\hline After sales service & Geographical location & Product appearance \\
\hline Amount of past business & Impression & Production facilities and capacity \\
\hline Attitude & JIT capability & Quality \\
\hline Catalog technology & Labor relations & Reciprocal arrangements \\
\hline Communication system & Maintainability & Reputation and position in industry \\
\hline Delivery & Management and Organization & Response to customer request \\
\hline Ease-of-use & Operational controls & Technical capability \\
\hline E-commerce capability & Packaging ability & Technical support \\
\hline Environmentally friendly products & Performance history & Training aids \\
\hline Financial position & Price & Warranties and claims \\
\hline
\end{tabular}

These aspects, highlight two peculiarities of the suppliers selection: 1) It is a multi-criteria problem; 2) the need to adopt models able to work both with quantitative and qualitative variables.

For these reasons, a wide spectrum of methodologies to deal with the problem has been developed and applied during the last years. In the next section, on the base of the literature survey, the different approaches proposed in the literature to deal with the suppliers selection problem will be highlighted. 


\section{Lite rature survey}

As mentioned before, in the last years a strong interest in the literature on the SSP occurred. Scholars and practitioners of several countries have been involved in the development of analysis, theoretical methodologies and practical application about the problem. This interest is proved by the large number of papers appeared in the recent years on the most significant scientific journals. For this reason we performed a survey in order to understand the characteristics of the research demand about the problem and to identify perspectives for further studies.

The survey has been carried out through a search of papers recently published on international scientific journals. In order to select the papers to be analyzed, we used the web-based tool Google Scholar that includes all the most popular academic search engines. In particular we considered all the scientific papers, published between 2003 and 2008, provided by the advanced search finding the exact phrases "Supplier Selection" and "Vendor Selection" in the title or among the key-words or within the abstract of the articles.

\section{General results}

With reference to the period 1986-2008, an historical trend about Supplier Selection literature is reported in Figure 1. Data for the 1986-2002 period have been retrieved from Bhutta (2003) work.

The trend1 reveals the significant attention devoted to the SSP due to the considerable total number of papers (218) with a relevant positive trend in the last years. The papers are hosted on a total number of 75 scientific journals.

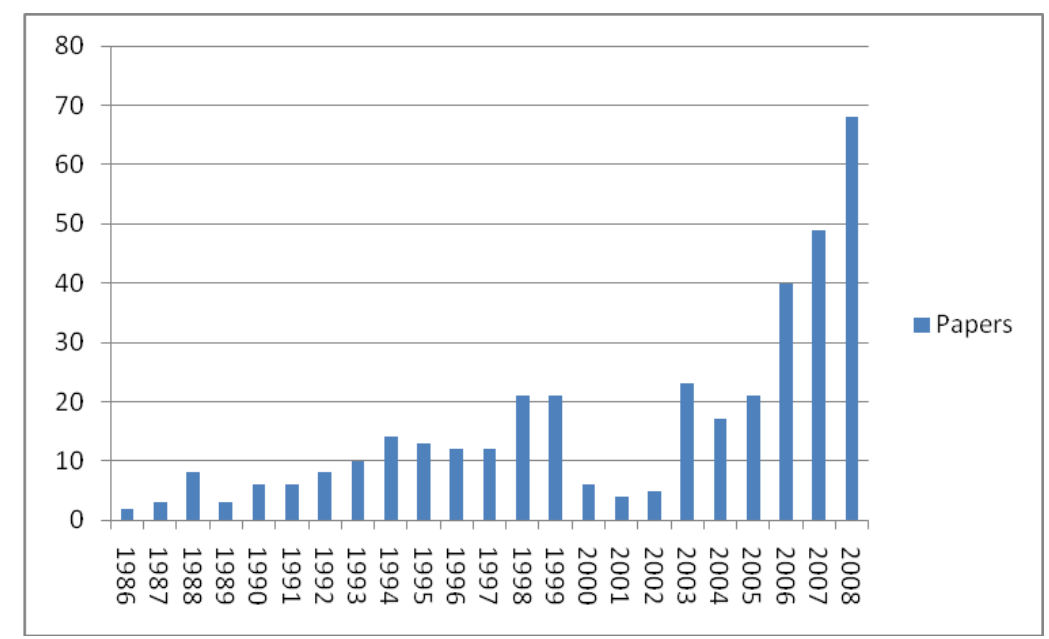

Figure 1 - Supplier Selection Papers Historical Series (2003-2008)

Stressing the analysis on the geographical expression of the interest on the base of the country where the institution of the first author is based, it emerges that neglecting USA which are the major contributor with 49 papers, Taiwan (37) and China (27) appear as the most prolific followed by further Asian countries, like Turkey (21), India (16) and Iran (14) while European scholars and institutions seem to be less involved in this field of study (Table 2). These aspects may be explained by the fact that a stronger attention comes from the geographical areas that, more than others, have been involved, in the last decade, in innovation and transformation processes of their manufacturing systems.

\begin{tabular}{|c|c|c|c|c|c|c|c|c|c|c|c|}
\hline Country & US A & Tai wan & China & Turkey & India & Iran & UK & Italy & Germany & Others & Total \\
\hline No. papers & 49 & 36 & 27 & 21 & 16 & 14 & 8 & 8 & 6 & 33 & 218 \\
\hline
\end{tabular}

Research fields

Selected papers are focused on various aspects of the SSP. In particular the most popular topics concern the strategic role played by the SSP to improve the performance of the entire supply chain, the definition of the more appropriate attributes and variables to be considered in the selection 
process, the choice of suitable methodologies to rank suppliers, the construction of practical tools to implement the decisional process. For this reason, scientific journals hosting papers on this problem refer to various research fields and scientific areas.

Nevertheless the relevant number of journals (75) publishing papers on the SSP, it is possible to individuate some journals, which host the most significant number of contributions. Table 3 shows the top five contributors, which account for 75 papers (34.40\% of the total number).

\begin{tabular}{|l|r|}
\hline Scientific journals & Papers \\
\hline International Journal of Production Economics & 22 \\
\hline Expert Systems with Applications & 19 \\
\hline International Journal of Production Research & 15 \\
\hline European Journal of Operational Research & 10 \\
\hline Journal of Purchasing and Supply Management & 9 \\
\hline Total Number of Papers & 75 \\
\hline Percentage on Total Number of Papers & $34.40 \%$ \\
\hline
\end{tabular}

Table 3 - Top 5 contributors for publications in the period 2003-2008

The list includes journals from different areas, like Manufacturing (International Journal of Production Economics, International Journal of Production Research), Logistics (Journal of Purchasing and Supply Management), Operations Research (European Journal of Operational Research), Computer Science (Expert Systems with Applications). Papers also appear on journals about Management and Information Sciences. This fact highlights that the interest for the topic involves different research fields in the attempt to face the SSP from multiple points of view and with different methodologies.

\section{Methodologies}

The variety of the literature is also demonstrated by the numerous approaches proposed to analyze and solve the problem. Recently Ha and Krishnan (2008) have proposed a classification of the employed approaches in dealing with the SSP. Starting from the classification of Ha and Krishnan, on the base of the 218 papers analyzed, it is possible to identify a taxonomy that includes two main categories (single or pure models and combined models) and seven sub-categories.

The first category (pure or single models) concerns models that use a single methodology. It encompasses four sub-categories:

- mathematics;

- statistics;

- artificial intelligence;

- qualitative and descriptive models.

The second category (combined models) includes models that use more then one methodology in the same framework. It encompasses three sub-categories:

- mathematics combined models;

- artificial intelligence combined models;

- hybrid combined models, namely models using methodologies belonging to different subcategories.

According to this classification, surveyed papers have been categorized as depicted in Figure 2. 


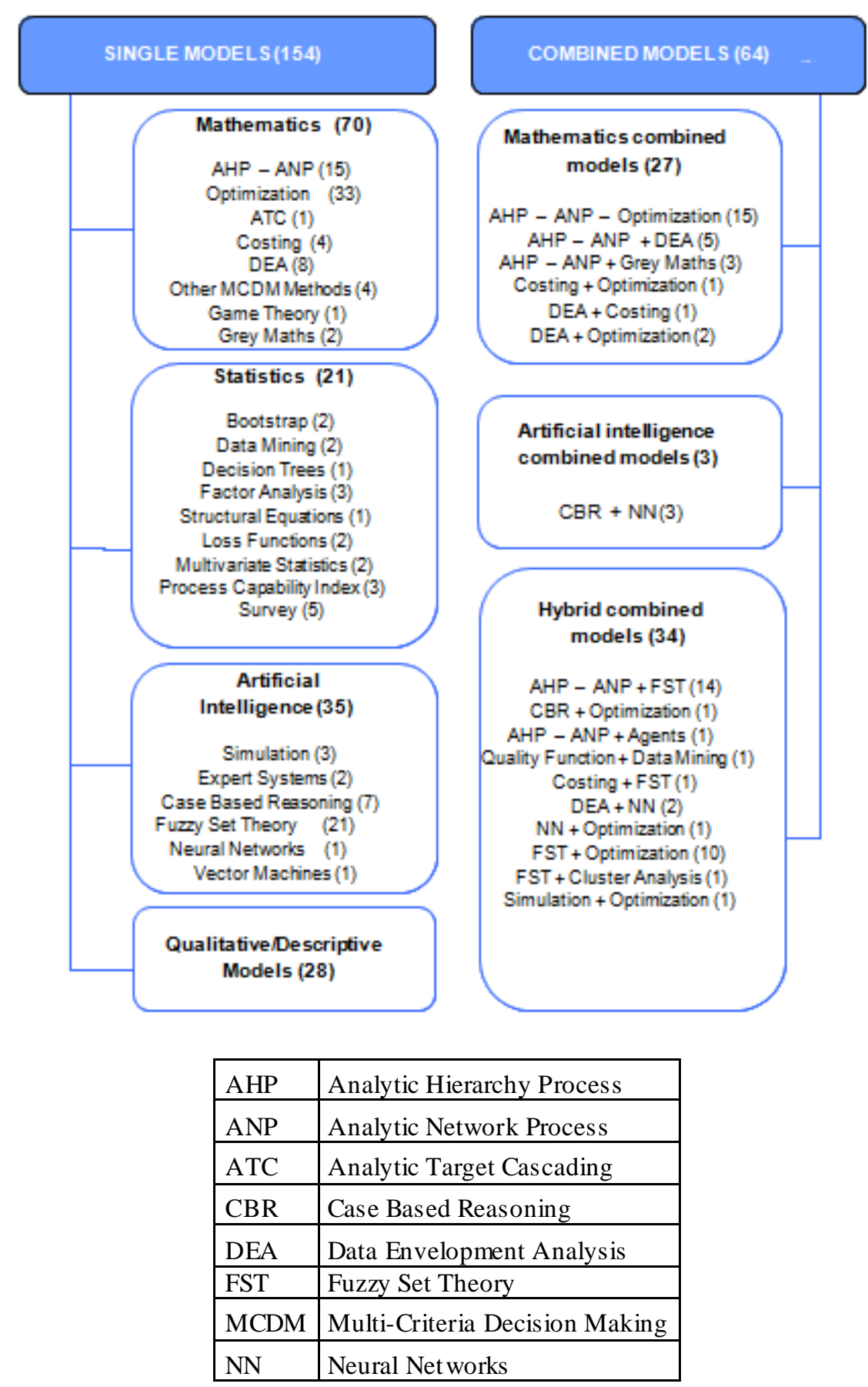

Figure 2-Taxonomy of methodologies used in the suppliers selection process.

The analysis of the results shows the large use of mathematical approaches: in particular 129 out of $218(51.2 \%)$ papers were developed using mathematical methodologies (Optimization techniques, Multi-Criteria Decision Making methods, etc.). Specifically, 70 papers use single mathematical methodologies, 27 combined mathematical methodologies, and 32 hybrid combined methodologies. More in detail, 53 papers use models based on the AHP approach, namely the $43.1 \%$ of papers that use mathematical methodologies and the $24.3 \%$ of the entire sample of papers. 


\section{The use of AHP and its variants for the SSP}

As illustrated in Figure 2, AHP-based methods represent one of the most used methodology to tackle the SSP. In particular, even though only 17 papers used AHP/ANP in a pure way (compared with 33 Optimization and 21 FST), the importance of AHP is stressed by the fact that it is the most flexible methodology. In fact, AHP is used in combination with other approaches in 38 papers (compared with 21 Optimization and 26 FST). In total, 55 papers over 218 employ AHP and/or ANP in a pure way or in combination with other approaches (compared with (54 Optimization and 47 FST). We analyzed these papers in order to underline the suitability of the AHP-based models to describe the problem and also to indicate some further research perspectives.

\section{General results}

In Table 4 the number of papers using AHP and its variants compared to the total number of papers on the SSP is shown. The data reveal that in the last years the application of AHP and its variants is quite frequent and represent almost one third of the papers.

33 out 55 (58.82\% of the total) papers turned out to be published on ISI ranked journals: calculating the average impact factor as weighted sum of journals' impact factors, assuming the number of papers published by the specific journal as weight, it results an average impact factor of 0.951 (utilizing data from 2008 Journal Citation Report).

\begin{tabular}{|c|c|c|c|c|c|c|c|}
\hline Year & $\mathbf{2 0 0 3}$ & $\mathbf{2 0 0 4}$ & $\mathbf{2 0 0 5}$ & $\mathbf{2 0 0 6}$ & $\mathbf{2 0 0 7}$ & $\mathbf{2 0 0 8}$ & Total \\
\hline Papers using AHP & 6 & 2 & 3 & 9 & 14 & 21 & 55 \\
\hline Total number & 23 & 17 & 21 & 40 & 49 & 68 & 218 \\
\hline \% of papers using AHP & 26.09 & 11.76 & 14.28 & 22.50 & 28.57 & 30.88 & 25.22 \\
\hline
\end{tabular}

Table 4 - Historical series of papers using AHP and its variants about the SSP

Considering the geographic origin of the papers (Table 5). AHP-based methods are mostly used in emerging economies (Turkey, Taiwan, China, India) testifying the great interest for this technique in countries where manufacturing is still the prominent economic activity.

\begin{tabular}{|c|c|c|c|c|c|c|c|}
\hline Country & Turkey & Tai wan & China & US A & India & Others & Total \\
\hline No. papers & 13 & 11 & 9 & 9 & 8 & 5 & 55 \\
\hline
\end{tabular}

\section{Research fields}

The 55 analyzed papers have been published on journals belonging to different disciplines, coherently with the multi-disciplinary nature of the Supplier Selection Problem already underlined in the previous section (Table 6).

\begin{tabular}{|l|r|}
\hline Area & Papers \\
\hline Operations Research & 8 \\
\hline Management & 11 \\
\hline Computer Science & 4 \\
\hline Information Sciences & 6 \\
\hline Manufacturing & 17 \\
\hline Logistics & 9 \\
\hline
\end{tabular}

Table 6 - Classification of Papers about Supplier Selection using AHP by journal area (2003-2008). 
In Table 7 the journals which have hosted more than two papers about the application of AHP-based methods are indicated. The major contributor is given by Expert Systems with Applications (5) that published a special issue on the SSP. The top six contributors (papers accounting for at least three papers) account for 21 out of 55 papers.

\begin{tabular}{|l|c|}
\hline Journal & Published pape rs \\
\hline Expert Systems with Applications & 5 \\
\hline International Journal of Production Research & 4 \\
\hline Computers \& Industrial Engineering & 3 \\
\hline International Journal of Advanced Manufacturing Technologies & 3 \\
\hline International Journal of Production Economics & 3 \\
\hline Omega & 3 \\
\hline Supply Chain Management: An International Journal & 2 \\
\hline Industrial Management \& Data Systems & 2 \\
\hline Information Sciences & 2 \\
\hline International Journal of Information Technology \& Decision Making & 2 \\
\hline International Journal of Services and Operations Management & 2 \\
\hline Journal of Manufacturing Technology Management & 2 \\
\hline Logistics Information Management & 2 \\
\hline Proceedings of the Institutions of Mechanical Engineers, Part B & 2 \\
\hline Total Papers & 37 \\
\hline
\end{tabular}

Table 7 - Journals which has hosted more than two papers about the application of A HP-based methods on the SSP (2003-2008).

\section{Objective}

With reference of the objective, most of the papers (38 out of 55) are focused on the ranking of a set of vendors. This papers offer a wide variety of structures (hierarchic or network) characterized by different numbers and typologies of attributes (criteria). Considering the papers in which a classical hierarchical schema is adopted, the average number of criteria considered in the first level is 6.19. This testifies the suitability of AHP to model and solve complex decision making problems. In tackling the ranking problem, in general, it is assumed that all suppliers in the list satisfy buyer's requirements: in other words the suppliers are considered feasible and there is no need to previously verify constraints satisfaction conditions. The remaining papers (17) deal with the definition of the optimal order allocation among a set of suppliers, previously ranked, in order to optimize a given objective function. These papers face situations in which no supplier is capable in providing the buyer with required quantities, as there are some limitations on suppliers' capacity, quality and delivery. It is supposed that buyers have to decide which suppliers are the best and how much should be purchased from each selected supplier. In order to demonstrate the suitability of the proposed approaches, most of the papers include the illustration of real case studies (35) rather than numerical examples (17). Two papers presents questionnaires to validate the derived hierarchical schema.

\section{Methodologies}

The analyzed papers contain many variants of the original AHP. Together with works using AHP and/or ANP in the classical version, very often the method is applied in combination with other mathematical approaches. 


\begin{tabular}{|l|c|}
\hline Version & Published Pape rs \\
\hline AHP + Optimization methods & 17 \\
\hline Pure AHP (ANP) & 15 \\
\hline AHP + Fuzzy Set Theory & 14 \\
\hline AHP + Data Envelopment Analysis & 5 \\
\hline AHP + Grey Mathematic & 3 \\
\hline AHP + Agent Based Simulation & 1 \\
\hline Total & 55 \\
\hline
\end{tabular}

Table 8 - Classification of papers using AHP (2003-2008) in Supplier Selection Problem by methodology.

In Table 8 it is shown the number of the appeared papers for each implemented version. Moreover, a synthetic description of the papers belonging to each version is provided.

\section{The Analytic Hierarchy Approach}

The AHP is a general theory of measurement that depends on the values and judgments of individuals and groups. More precisely, judgments are brought together according to a multilevel hierarchic structure to derive priorities. The major advantage of the hierarchical structure is that it allows for a detailed, structured and systematic decomposition of the overall problem into its fundamental components and interdependencies, with a large degree of flexibility. The AHP has found its widest applications in multi-criteria decision making, in planning and resource allocation and in many other fields (see for instance Byun, 2001; Ngai 2003; Sarkis and Talluri, 2004). This methodology is made up of the following steps.

- Structuring of the problem into a hierarchy. In general hierarchies concern the distribution of a property (the goal) among the elements being compared, to judge which one influences or is influenced more. In the SSP, the goal is the evaluation of suppliers and, then, this phase consists of individuating the hierarchy of attributes and indexes to measure suppliers' characteristics.

- Comparative judgment. The aim is to measure the relative importance of the elements (attributes, indexes) to the overall goal. The question to ask when comparing two elements is "how much important is one of the two elements with respect to the goal of the problem?". In the SSP the objective is the customer and the aim is to investigate on his perceptions; in practice the output of this phase is a priority vector associated to the set of elements.

- Synthesis of the priorities. The objective of this phase is to derive a total or global ratio scale score for each alternative starting from the measured scores and the calculated priorities of each element. In the SSP it represents a model for suppliers' evaluation.

As the hierarchical framework did not let one deal with problems characterized by more sophisticated and complex interactions and dependencies, an evolution of the original methodology, the so called ANP (Analytic Network Process) has been proposed (Saaty, 2001) based on the replacement of the hierarchies with networks.

The massive diffusion of these techniques has stimulated the development of hybrid approaches in which one or more steps of the AHP and/or ANP are performed through other mathematical methodologies such as Fuzzy Set theory, Data Envelopment Analysis or further optimization approaches.

AHP + Fuzzy Set Theory

The AHP is based on pairwise comparisons expressed by numerical judgments based on a semantic ratio scale. In the literature there have been various proposals to try to improve this aspect through forms of "fuzzification". Nevertheless, general critic isms have been addressed towards the use of fuzzy numbers especially when it is applied indiscriminately as an approach to express certain and crisp judgments (Saaty and Tran, 2007). However, there is a growing interest in combining fuzzy set theory with AHP in dealing with the SSP. 
In fuzzy AHP modeling, fuzzy rather than crisp ratios are used for pair-wise comparisons. Suppose that a buyer wants to compare suppliers based on some criteria.

Assume that one of the criteria is 'service performance'. If the buyer had to perform pair-wise comparisons using normal AHP in order to build a comparison matrix, then he/she would have to choose a score from 0 to 9 to show how one supplier compares to another in terms of 'service performance'. Although the comparison scales provide flexibility for a decision maker to set scores, in some cases this flexibility does not guarantee a satisfactory decision. A fuzzy approach, on the other hand, captures the uncertainty in the decision maker's mind. According to Bottani and Rizzi (2005) the adoption of the fuzzy approach allows decision makers expressing ill-defined judgments such as "the relative importance of a criterion versus another is about double", or "a supplier performance versus one criterion is either in a range or almost in a range".

Apart from using different types of fuzzy numbers, several approaches for deriving priorities from fuzzy pair-wise comparison matrices have been developed. The earliest work in fuzzy AHP appeared in van Laarhoven and Pedrycz (1983), which utilized fuzzy ratios described by triangular membership functions in building pair-wise comparison matrices; final priority vectors were derived utilizing a Fuzzy Logarithmic Least Squares Method. Buckley (1985) determines fuzzy priorities of comparison ratios whose membership functions are trapezoidal; in doing this, he provides an adaptation of the geometric mean approach to the fuzzy case in order to derive priorities. Chang (1996) introduce a metric for estimating the prevalence of an element on the other within the pair-wise comparison matrix, namely the fuzzy synthetic extent. Mikhailov (2003) provides an analysis of the drawbacks with constructing fuzzy comparison matrices, suggesting a Fuzzy Preference Programming technique to derive priorities. A listing of the different extant approaches (developed by Benyoucef and Canbolat, 2007) is reported in Table 9.

\begin{tabular}{|l|l|l|}
\hline Paper & Fuzzy AHP method & Fuzzy Number \\
\hline van Laarhoven and Pedrycz (1983) & Fuzzy Logarithmic Least Squares Method & Triangular \\
\hline Buckley (1985) & Fuzzy geometric mean method & Trapezoidal \\
\hline Cheng and Mon (1994) & Interval arithmetic & Triangular \\
\hline Chang (1996) & Synthetic extent analysis & Triangular \\
\hline Xu (2000) & Fuzzy Least-Squares Priority Method & Triangular \\
\hline Mikhailov (2003) & Fuzzy Linear and non-LP method & Triangular \\
\hline
\end{tabular}

Table 9 - Fu zzy AHP methods

In the period under investigation, several applications of Fuzzy AHP have been developed to deal with the supplier selection problem. Out of the 14 examined papers that present the utilize of Analytic Hierarchy Process in combination with Fuzzy Set Theory, 13 utilize versions of AHP that embed fuzzy ratios for pair-wise comparisons. In particular, papers can be further classif ied according to the particular Fuzzy AHP method employed, as shown in Table 10. Synthetic extent analysis (with 8 papers) seems to be the most utilized approach for deriving priorities.

Kumar et al. (2008) develop an integrated approach using Analytic Hierarchy Process (AHP) and Fuzzy Linear Programming (FLP) for supplier selection and quota allocation problem. AHP is used to rate the suppliers, while FLP is used to allocate the quota to the suppliers. In FLP, multiple conflicting objectives with some constraints of buyers and suppliers are considered to optimze the order quantities.

\begin{tabular}{|l|l|l|}
\hline Fuzzy AHP method & Pape rs & Authors \\
\hline Synthetic extent analysis & 8 & $\begin{array}{l}\text { Buyukozkan et al. (2008), Chan and Kumar (2007), } \\
\text { Chan et al. (2008), Haq and Kannan (2006a), Kahraman } \\
\text { et al. (2003), Lee (2008), Lee et al. (2008), Sevkli et al. } \\
(2008) .\end{array}$ \\
\hline Fuzzy geometric mean method & 2 & Yang et al. (2008), Zaim et al. (2003). \\
\hline
\end{tabular}




\begin{tabular}{|l|l|l|l|}
$\begin{array}{l}\text { Fuzzy Logarithmic Least } \\
\text { Squares Method }\end{array}$ & 1 & Önüt et al. (2008). \\
\hline $\begin{array}{l}\text { Fuzzy Linear and non-LP } \\
\text { method }\end{array}$ & 1 & Benyoucef and Canbolat (2007) \\
\hline Interval arithmetic & 1 & Bottani and Rizzi (2005) \\
\hline
\end{tabular}

Table 10 - Su mmary of papers integrating AHP and Fu zzy Set Theory

\section{AHP + Optimization methods}

AHP-ANP is also used very often in combination with optimization methods. In particular AHP is used in combination with Integer Programming (Linear, Non-Linear, Mixed) (Kokangul and Susuz, 2008; Mendoza and Ventura, 2008; Yu and Tsai, 2008; Wang et al., 2005; Wu et al., 2008a) and Multi-Objective (Linear, Non-Linear, Integer and Goal) Programming (Çebi and Bayraktar, 2003; Demirtas and Ostun, 2007 and 2008; Ozgen, 2008; Percin, 2006; Ting and Cho, 2008; Xia and Wu, 2007; Venkata Rao, 2007).

In general, the combination between AHP and optimization methods is utilized to deal with deal the definition of the optimal order allocation among a set of suppliers. Suppliers are ranked utilizing AHP priorities; then, as no supplier is capable in providing the buyer with required quantities, the optimization model provides estimates on how much should be purchased from each selected supplier in order to maximize a given objective function that can represent, for example, the total value of purchasing weighted on suppliers' priorities. AHP can be also used to derive the weights for a multicriteria objective function including several performance criteria measures.

\section{Pure AHP (ANP)}

Basic versions of AHP and ANP are still widely used in the literature to deal with the SSP. All these papers, applying the methodology at its simplest level, do not take into account any kind of constraint about suppliers. Thus, these papers face the SSP from a ranking perspective, just providing a final standing of different suppliers.

The hierarchical schema adopted is composed by four hierarchical levels (main goal; attributes; characteristics; alternatives). To rank the suppliers, pairwise comparisons among suppliers themselves is used (Bayazit, 2006; Chan, 2003; Chan and Chan, 2004; Chin et al., 2006; Gencer and Gurpinar, 2007; Hou and Sou, 2006 and 2007; Levary, 2007 and 2008; Schoenherr et al., 2008; Wu et al. 2008b).

Onesime et al. (2004) and Pi and Low (2006) derive priorities for the hierarchical schema of AHP through pairwise comparisons among its elements, while derive supplier scores for each characteristics through the utilization of indicators based on a Quality Function approach.

\section{AHP + Data Envelopment Analysis}

Data Envelopment Analysis (DEA) is an approach for evaluating the performance of a set of entities which convert multiple inputs into multiple outputs. DEA employs Linear Programming for defining a best practice frontier that can be used as a benchmark for efficiency measures.

In the case of supplier selection, this requires construction of a benchmark (the frontier) and the measurement of the distance between suppliers themselves in a multi-dimensional framework. The following assumptions are made for the benchmark:

- positive weights, in the sense that the higher the value of a given individual indicator, the better for the corresponding supplier;

- non-discrimination of suppliers which are the best in any single dimension (individual indicator), thus ranking them equally;

- a linear combination of the best performers is feasible, i.e. convexity of the frontier.

-

This methodology is used in combination with the AHP in a multi-phase decision process in which both quantitative and qualitative attributes are involved. Generally, AHP is executed to appraise 
suppliers on the ir qualitative benefits, generating quantitative data from these qualitative dimensions. Secondly, DEA is used to synthesize the data to achieve a ranking of the suppliers.

Weber (1996) has shown the efficacy of using Data Envelopment Analys is (DEA) in Supplier selection problems especially when multiple conflicting criteria have to be considered.

Recent examples of these applications can be found in Liu and Hai (2005), Ramanathan (2007), Saen (2007), Sevkli et al. (2007), Hasan et al. (2008).

\section{AHP + Grey Mathematics}

Grey Theory (GT) is one of the methods used to study uncertainty based on the presence of systems with information known partially (grey systems). The integration of GT and AHP is quite similar to the development of fuzzy AHP: in the composition of the pairw ise judgment matrices, the inputs are considered to be grey numbers. Yang and Chen (2006), Haq and Kannan (2006b and 2007) provide examples of this application.

\section{AHP + Agent Based Simulation}

Chen and Huang (2007) propose an integration of AHP and Agent-Based Modeling. Suppliers and customers are represented by agents that negotiate terms and conditions of an agreement. AHP is used to determine traders' relative preferences and to evaluate supplier criteria during the negotiation.

\section{Discussion}

An analysis of the literature reveals that a large number of researches have been devoted to the development of different kind of methodologies to cope with the SSP.

In particular, AHP and its derived approaches, turns out to be one of the most popular methodologies for facing SSP. The extreme suitability of AHP to SSP can be explained by three distinctive characteristics, listed by Chan (2004):

- its ability to handle both tangible and intangible attributes;

- its ability to structure the problems, in a hierarchical manner, to ga in insights into the decision-making process;

- its ability to monitor the consistency with which a decision maker makes a judgment;

- its ability to provide a synthetic score for each supplier.

However, even if Analytical Hierarchy Process is a widely accepted methodology in the literature, some drawbacks are highlighted by Chan (2004) as follows:

- Its use is not straightforward for practitioners;

- Consensus may need to be reached in aggregating individual judgments for pair-wise comparison matrices;

- There is no single hierarchy for most supplier selection problems;

- The reliability of the outcome depends not only on the quality of the data, but also on know ledge and judgments of decision-makers.

Indeed, the analysis of the papers highlights that transferring theoretical models in practical application is a non easy problem. In particular, in the case of the AHP methodology, many problems arise. The first issue concerns the fact that the supplier selection system must be tailored on a specific technological philiere or component. This means that it is not possible to identify a set of attributes that are applicable for the whole supply system of a specific customer, but they depend on what process they are involved with, confirming Chan (2003) criticisms. Therefore, the resulting model is employable to study the supplier selection problem for just a component. This means that developing a model that can be used for real purposes requires a so high customization degree that causes a loss of generality. In other words, in the application of the AHP methodology to the supplier selection problem there is a trade-off between usability and generality.

Furthermore, an issue regards the distance between the literature and firms' reality. Specifically, the literature review has shown that often firms' management doesn't recognize the list of attributes proposed by Ha and Krishna (2008) as applicable in their specific context. So, further definition and specification of the criteria are needed. 
Moreover, managers interviewed to express their judgments to derive the priority schema formulate their opinions depending on the functional area they belong to and its specific strategic objective. Two aspects emerge from this point: managers coming from different areas could express very different judgments, and this can affect the consistence of the aggregate pair-wise comparison matrices; thus, it's relevant the choice of the managers to be interviewed. As regards the interviewer, his degree of knowledge of the methodology can affect the results of the interview as well.

Finally, since the hierarchical schema and the priority vectors are identified and evaluated on the basis of the strategic objectives of the customer, any change in the latter implies a revision of the model. Thus, any supplier selection model should be a dynamic one, in order to take in account this aspect. This means that, once the model has been built, it has just to be considered as a starting point to be continuously monitored and improved.

\section{Final considerations}

This paper highlighted that AHP based tools for SSP are generally characterized by three aspects:

- High level of specificity. The AHP models must be tailored on the specific context, that is identifying the object of the supplying and the customer needs. If changes the object of supplying also the customer needs, the hierarchical structure, the variables involved and their weights must be modified.

- High level of costs. The implementation of such a model ask for a start up investment in terms training of human resources involved.

- High level of maintenance. If changes the customer strategy, the needs of the customer change. Consequently the weights of the variables involved in the model must be modified.

From these considerations two main questions emerge:

- Why customers should use the AHP models?

- In what context AHP models should be preferred to qualitative approaches, which appear to be typified by low level of costs and high level of flexibility?

Considering the first question, there are at least three good reasons to use AHP based model:

- Learning, as setting up such a model allows to know both the needs of the customer and how a supply chain systems really works.

- Transparence, as the presence of a clear framework on which the selection is based gives the supplier a tool to understand how it is evaluated and at the same time, gives the customer a coherent and not subjective tool of evaluation. Moreover, this could also lead to a sideeffect: the motivation that could push both the suppliers and the customers to achieve better performances

- Managerial issues, since AHP based models allow customers to identify strengths and weaknesses of their supply system, in this way customers are facilitated to manage the whole supply chain and realign constantly the aim of the supplier to its aim.

Regarding the second question, it is evident that AHP based models find their main field of application in industries characterized by high technological and/or complexity level, that is in context where supply chain usually gives a robust contribution in terms quality and of added value. In these industries customers have a strong interest to invest resources to improve their supply chain performance. By contrast, in industries where the supply chain gives a low contribution in term of added value and where the object of supplying is not complex, qualitative models seem more appropriate since they are built on the base of the experience of experts and on the base of qualitative judgments, and consequently they do not ask neither high costs of development nor the involvement of a number of resources in the decisional process.

These final aspects underline why, although the number of applications for supplier selection is growing, firms are not likely to use these tools because they are often too far from the corporate world. Thus, the most of the firms approaches the supplier selection problem just employing qualitative judgment from some experts, as also stated by de Boer and van der Wegen (2003). 


\section{REFERENCES}

Altinoz C. (2008). Supplier selection for industry: a fuzzy rule-based scoring approach with a focus on usability. International Journal of Integrated Supply Management, vol.4(3), pp. 303-321.

Bayazit O. (2006). Use of analytic network process in vendor selection decisions. Benchmarking: An International Journal, vol. 13(5), pp. 566-579.

Benyoucef M., Canbolat M. (2007). Fuzzy AHP-based supplier selection in e-procurement. International Journal of Services and Operations Management, vol.3(2), pp. 172-192.

Bottani E., Rizzi A. (2005). A fuzzy multi-attribute framework for supplier selection in an eprocurement environment. International Journal of Logistics Research and Applications, vol.8(3).

Buyukozkan G., Feyzioglu O., Nebol E. (2008). Selection of the strategic alliance partner in logistics value chain, International Journal of Production Economics, vol.113, pp.148-158.

Byun D.H. (2001). The AHP approach of selecting an automobile purchase model. Information and Management, vol.38, pp.289-295.

Çebi F., Bayraktar D. (2003). An integrated approach for supplier selection. Logistics Information Management, vol.16(6), pp.395-400.

Chan F.T.S. (2003). Interactive selection model for supplier selection process: an analytical hierarchy process approach. International Journal of Production Research, vol. 41(15), pp. 3549-3579.

Chan F.T.S., Chan H.K. (2004). Development of the supplier selection model - a case study in the advanced technology industry. Proceedings of the Institution of Mechanical Engineers, Part B, vol. 218, pp.1807-1824.

Chan F.T.S., Kumar N. (2007). Global supplier development considering risk factors using fuzzy extended AHP-based approach. Omega, vol.35, pp. 417 - 431.

Chan F.T.S, Kumar N., Tiwari M.K., Lau H. C. W., Choy K. L. (2008). Global supplier selection: a fuzzy-AHP approach. International Journal of Production Research, vol.46(14), pp. 3825-3857.

Chan T.C.T.; Chin K.S. (2007). Key success factors of strategic sourcing: An empirical study of the Hong Kong toy industry. Industrial Management and Data Systems, vol.107(9), pp. 1391-1416.

Chen Y.M., Huang P.N. (2007). Bi-negotiation integrated AHP in suppliers selection. International Journal of Operations \& Production Management, vol.14(5), pp.575-593.

Chin K.S., Yeung I.K., Pun K.F. (2006). Development of an assessment system for supplier quality management. International Journal of Quality \& Reliability Management, vol.23(7), pp. 743-765.

de Boer L., Labro E., Morlacchi P. (2001). A review of methods supporting supplier selection, European Journal of Purchasing \& Supply Management, vol.7, pp.75-89.

de Boer L., van der Wegen L.L.M. (2003). Practice andpromise of formal supplier selection: a study of four empirical cases. Journal of Purchasing \& Supply Management, vol.9, pp.109- 118.

Demirtas E.A. , Ustun O. (2007). Analytic network process and multi-period goal programming integration in purchasing decisions. Computers \& Industrial Engineering.

Demirtas E.A., Ustun O. (2008). An integrated multiobjective decis ion making process for supplier selection and order allocation. Omega, vol.36, pp.76-90.

Dickson G. W. (1966). An analysis of vendor selection systems and decisions. Journal of Purchasing, vol.2, n.1, pp.5-17.

Esposito E.., Passaro R. (2009). The evolution of supply chain relationships: An interpretative framework based on the Italian inter-industry experience. Journal of Purchasing and Supply Management, vol.15(2), pp.114-126.

Gencer C., Grupinar D. (2007). Analytic network process in supplier selection: A case study in an electronic firm. Applied Mathematical Modelling, vol.31, pp.2475-2486.

Gules H.K., Burges T.F. (1996). Manufacturing technology and the supply chain. European Journal of Purchasing \& Supply Management, vol.2, n.1, pp.31-38.

Ha H.S., Krishnan R. (2008). A hybrid approach to supplier selection for the maintenance of a competitive supply chain. Expert Systems with Applications, vol. 34, pp.1303-1311.

Hasan A.M., Shankar R., Sarkis J. (2008). Supplier selection in an agile manufacturing environment using Data Envelopment Analysis and Analytical Network Process. International Journal of Logistics Systems and Management, vol.4(5), pp.523-550. 
Hou J., Su D. (2006). Integration of Web Services technology with business models within the total product design process for supplier selection. Computers in Industry, vol. 57, pp.797-808.

Hou J., Su D. (2007). EJB-MVC oriented supplier selection system for mass customization. Journal of Manufacturing Technology Management, vol.18(1), pp.54-71.

Kahraman C., Cebeci U., Ulukan Z. (2003). Multi-criteria supplier selection using fuzzy AHP. Logistics Information Management, vol.16(6), pp. 382-394.

Kamann D.F., Bakker E.F. (2004). Changing supplier selection and relationship practices: a contagion process. Journal of Purchasing \& Supply Management, vol.10, pp.55-64.

Kokangul A., Susuz Z. (2008). Integrated analytical hierarch process and mathematical programming to supplier selection problem with quantity discount. Applied Mathematical Modeling, vol. 33(3), pp. 1417-1429.

Krause D.R., Ellram L. M. (1997). Success factors in supplier development. International Journal of Physical Distribution and Logistics Management, vol.27, n.1, pp.39-52.

Kumar P., Shankar R., Yadav S.S. (2008). An integrated approach of Analytic Hierarchy Process and Fuzzy Linear Programming for supplier selection. International Journal of Operational Research, vol.3(6), pp.614-631.

Lamming R., Cous ins P.D. Notman D.M., (1996). Beyond supplier evaluation. Relationship evaluation programmes. European Journal of Purchasing and Supply Management, vol. 2, n.4, pp.173-181.

Lee A. H. I. (2008). A fuzzy supplier selection model with the consideration, Expert Systems with Applications, doi:10.1016/j.eswa.2008.01.045.

Lee A.H.I, Kang H.Y., Chang C.T. (2008) Fuzzy multiple goal programming applied to TFT-LCD supplier selection by downstream manufacturers. Expert Systems with Applications, doi:10.1016/j.eswa.2008.08.044

Levary R.R. (2007). Ranking foreign suppliers based on supply risk. Production Planning and Control, vol.14(5), pp. 575-593.

Levary R.R. (2008). Using the analytic hierarchy process to rank foreign suppliers based on supply risks. Computers \& Industrial Engineering, vol.55, pp. 535-542.

Liu F.H.F., Hai H.L. (2005). The voting analytic hierarchy process method for selecting supplier. International Journal of Production Economics, vol.97 pp.308-317.

Mendoza A., Ventura J.A. (2008). An effective method to supplier selection and order quantity allocation. International Journal of Business and Systems Research, vol.2(1), pp.1-15.

Ngai E.W.T. (2003). Selection of web sites for online advertising using AHP. Information and Management, vol.40, pp.233-242.

Noorul Haq A., Kannan G. (2006a). Design of an integrated supplier selection and multi-echelon distribution inventory model in a built-to-order supply chain environment. International Journal of Production Research, vol.44(10).

Noorul Haq A., Kannan G. (2006b). An Integrated Approach For Selecting A Vendor Using Grey Relational Analysis. International Journal of Information Technology \& Decision Making, vol.5(2), pp. 277-295.

Noorul Haq A., Kannan G. (2007). A hybrid normalised multi criteria decision making for the vendor selection in a supply chain model. International Journal of Management and Decision Making, vol.8(5/6), pp. 601-622.

O'Neal C. (2006). Concurrent engineering with early supplier involvement: a cross functional challenge. Journal of Supply Chain Management, vol. 29, n.2, pp.2-9.

Onesime O.C.T., Xu X., Zhan D. (2004). A Decision Support System for Supplier Selection Process. International Journal of Information Technology \& Decision Making, vol.3(3), pp. 453-470.

Önüt S., Kara S.S., Isik E. (2008). Long term supplier selection using a combined fuzzy MCDM approach: A case study for a telecommunication company. Expert Systems with Applications, doi:10.1016/j.eswa.2008.02.045

Ozgen D., Onut S., Gulsun B., Tuzkaya U.R., Tuzkaya G. (2008). A two-phase possibilistic linear programming methodology for multi-objective supplier evaluation and order allocation problems. Information Sciences, vol.178, pp.485-500. 
Percin S. (2006). An application of the integrated AHP-PGP model in supplier selection. Measuring business excellence, vol. 10(4), pp. 34-49.

Pi W.N., Low C. (2005). Supplier evaluation and selection using Taguchi loss functions. International Journal of Advanced Manufacturing Technology, vol.26, pp.155-160.

Ramanathan R. (2007). Supplier selection problem: integrating DEA with the approaches of total cost of ownership and AHP. Supply Chain Management: An International Journal, vol.12(4), pp. 258-261. Saaty T.L. (1980). The Analytic Hierarchy Process. McGraw Hill International, New York.

Saaty T.L. (1994). Fundamentals of Decision Making and Priority Theory with the Analytic Hierarchy Process. RWS Publications; Pittsburg PA, pp 204-220.

Saaty T.L. (2001). The Analytic Network Process: Decision Making with Dependence and Feedback, RWS Publ., Houston.

Saen R.F. (2007). A new mathematical approach for suppliers selection: Accounting for nonhomogeneity is important. Applied Mathematics and Computation, vol.185, pp. 84-95.

Sarkara A., Mohapatrab P.K.J. (2006). Evaluation of supplier capability and performance: A method for supply base reduction. Journal of Purchasing \& Supply Management, vol.12, pp.148-163.

Sarkis J., Talluri S. (2004). Evaluating and selecting e-commerce software and communication systems for a supply chain. European Journal of Operations Research, vol.159, pp.318-329.

Schoenherr T., Rao Tummala V.M., Harrison T.P. (2008). Assessing supply chain risks with the analytic hierarchy process: Providing decision support for the offshoring decision by a US manufacturing company. Journal of Purchasing \& Supply Management vol.14, pp.100-111.

Sevkli M., Koh S.C.L., Zaim S., Demirbag M., Tatoglu E. (2007). An application of data envelopment analytic hierarchy process for supplier selection: a case study of BEKO in Turkey. International Journal of Production Economics, vol.45(9), pp. 1973-2003.

Sevkli M., Koh S.C.L., Zaim S., Demirbag M., Tatoglu E. (2008). Hybrid analytical hierarchy process model for supplier selection. Industrial Management \& Data Systems, vol.108(1), pp. 122-142.

Ting S.C., Cho D.I. (2008). An integrated approach for supplier selection and purchasing decisions. Supply Chain Management: An International Journal, vol.13(2), pp. 116-127.

Ting S.C., Cho D.I. (2008). An integrated approach for supplier selection and purchasing decisions. Supply Chain Management: an International Journal, vol. 13(2), pp.116-127.

Yang C.C., Chen, B.S. (2006). Supplier selection using combined analytical hierarchy process and grey relational analysis. Journal of Manufacturing Technology Management, vol.17(7), pp.926-941.

Yang J.L., Chiu H.N., Tzeng G.H., Yeh R.H. (2008). Vendor selection by integrated fuzzy MCDM techniques with independent and interdependent relationships. Information Sciences vol. 178, pp.4166-4183

Yu J.R., Tsai C.C. (2008). A decision framework for supplier rating and purchase allocation: A case in the semiconductor industry. Computers \& Industrial Engineering, vol.55, pp.634-646.

Xia W., Wu Z. (2007). Supplier selection with multiple criteria in volume discount environments. Omega, vol.35, pp. $494-504$.

Venkata Rao R. (2007). Vendor selection in a supply chain using analytic hierarchy process and genetic algorithm methods. International Journal of Services and Operations Management, vol.3(3), pp. 355-369.

Wang G., Huang S.H., Dismukes J.P. (2005). Manufacturing supply chain design and evaluation, International Journal Advanced Manufacturing Technology, vol.25, pp.93-100.

Wu W.-Y., Sukoco B.M., Li C.Y., Chen S.H. (2008a). An integrated multi-objective decision-making process for supplier selection with bundling problem. Expert Systems with Applications, doi:10.1016/j.eswa.2007.12.022.

Wu W.Y., Shih H.A., H.C. Chan (2008b). The analytic network process for partner selection criteria in strategic alliances. Expert Systems with Applications, doi:10.1016/j.eswa.2008.06.049.

Zaim S., Sevkli M., Tarim M. (2003). Fuzzy analytic hierarchy based approach for supplier selection. Journal of Euromarketing, vol. 12(3/4), pp.147-76. 